INFORMAL LOGIC

XI.3, Fall 1989

\title{
Two Traditions of Analogy
}

\section{WILLIAM R. BROWN Quinnipiac College}

There have been previous descriptions of two types of analogy. On dimensions other than the one I explore in the present article, Rhetoric and Speech Communication textbooks usually distinguish figurative analogy, which is "merely" illustrative or metaphorical, from literal analogy, which corresponds to what logic textbooks usually call analogy (Osborn and Osborn 305, Gronbeck 52-3, Cronkhite, 133-4, 171-2, Spurgin 214), and St. Thomas Aquinas distinguished analogy of attribution from analogy of proportion (Ferre, Lotz). On my dimension, which originated in Aristotle and was briefly identified by Whately (27-8) and by Mill (71), my explanation differs in fundamental ways from that of Ehninger and Brockriede (142-4) and of Michalos (347-52). The distinction I hope to demonstrate, exists, first of all, on the level of underlying logical form, then in purpose of discourse and in historical tradition, and ultimately in philosophical roots, a distinction between ways of seeing the world. Before attempting to explain this distinction, I must beg the reader's patience for preliminary discussion required by the great variation in treatment of the topic across disciplines and by the eclectic nature of my perspective toward these disciplines.

"There is no word," as John Stuart Mill remarked, "which is used more loosely, or in a greater variety of senses, than Analogy" (554). Analogy may be defined as "a comparison between things that are basically dissimilar made for the purpose of illuminating our understanding of the things being compared" (Chaffee 310). Or arguments from analogy may be treated as "another special case", in a chapter on induction and empirical generalization (Cederblom 201). The term "inductive analogy" is sometimes used, without being explicitly contrasted with any complementary term, but Waller does explicitly contrast "inductive argument by analogy" and "deductive argument by analogy" (222-3, 208-11). Analogy may move from the known to the unknown (Ross 208) or from particulars to particulars (Mill 1102). "Analogy in argument proves a point" (Levin 486), but "an analogy cannot prove anything, it can only hope to clarify"' (Barnett and Stubbs 505).

Conceptions of analogy vary from discipline to discipline. Whether one believes that an analogy can "prove" a point in an "argument" depends on whether one understands the words prove and argument in the logician's sense or in the rhetorician's sense, as well as depending on one's understanding of analogy itself. Freshman English handbooks appear to be assuming a definition similar to what Speech Communication texts say about figurative analogy. One handbook is an exception, containing a definition clearly recognizable as that of logicians (Legget 388).

The degree of esteem in which analogy in any of its traditions is held varies from discipline to discipline. The practice of some psychologists in the construction of SAT and IQ tests seems to reflect a belief in a relation between analogy and intelligence, a belief deriving from the psychology and philosophy of Associationism, transmitted by early psychologists like Bain, and expressed as follows by William James: 


\begin{abstract}
...some people are far more sensitive to resemblances, and far more ready to point out wherein they consist, than others are. They are the wits, the poets, the inventors, the scientific men, the practical geniuses. $A$ native talent for perceiving analogies is reckoned by Professor Bain, and by others before and after him, as the leading fact in genius of every order (I, 529-30).
\end{abstract}

On the other hand, a tendency to regard analogy as fallacious is also widespread. Mill's attitude, a derisive reversal of James's, is revealed in the following passage:

This very common aberration [overrating the probative force of analogy] is sometimes supposed to be particularly incident to persons distinguished for their imagination; but in reality it is the characteristic intellectual vice of those whose imaginations are barren.... To such minds objects present themselves clothed in but few properties; and as, therefore, few analogies between one object and another occur to them, they almost invariably overrate the degree of importance of those few (795).

Freshman English handbooks often follow Mill's precedent of treating "faulty (false) analogy" within a list of fallacies separated in the text from the definition and description of analogy.

I must state, as briefly as possible, the general assumptions from which I begin, for if left unstated, they will mystify readers who begin from other assumptions. For me, reasoning is something that goes on in people's minds (though much else that is not reasoning also goes on there), and argument is a communication of reasoning-an effort to get somebody else to reason the same way you do. Logic is not a set of instructions, or even guidelines, that people apply in order to reason. Nor is it the kind of direct representation of a behavioral or neurological process that a cognitive psychologist might attempt to reconstruct. Logic is a constructed model that attempts to account for some or all of reasoning and argument, like the model constructed by linguists to account for the natural gram- mar people have that enables them to speak a language. When logic is seen as having a normative rather than a descriptive function, it becomes evaluation, and in its narrowest possible sense it is nothing more than the evaluation of particular arguments and argument types. This narrowest sense is assuredly a legitimate one and one espoused by many logicians, but it is not the one I am applying in this article. My sense is the descriptive one.

Now to the two types of analogy. Analogy is often explained as a special kind of comparison (or similarity) between two objects (events, ideas, classes of objects, etc.) such that the possession in common of one (or more) characteristic (property, attribute, etc.) by both objects is believed to imply that the two objects probably have some other characteristic(s) in common. For instance, if two automobiles are in the same price range, one might infer by analogy that they are of comparable quality (or even the same color). Although usually not mentioned in such explanations, differences would seem to be as susceptible as similarities to analogical treatment. For instance, to say that if one automobile is more expensive than another, it is likely to be of a higher quality also, seems to me to be just as much an analogy as the previous example. In any case, the general sort of explanation I have just sketched defines analogy as something involving exactly two objects (or terms) and two or more characteristics of those objects. I shall designate analogy as so explained "predictive analogy." Readers of Informal Logic will have no difficulty recognizing this description as the one usually found in critical thinking and introduction to logic textbooks (Kahane 304-5, Cederblom 201, Barry 47-63, Manicas and Kruger 249-53, Runkle 216-29, Baum 291-5).

There is a different explanation which describes a form that I shall designate "proportional analogy." Analogy according to this explanation asserts that exactly four objects (rather than two) are related in a particular manner such that two of the objects 
have the same (or a similar) relationship to each other that the other two have to each other. This relationship may be based on a single attribute, a complex of attributes, or an ordered pair of attributes (as when one says that, just as the elephant surpasses the mouse in size, so does the hare surpass the tortoise in speed). A proportional analogy about automobiles might state, "As Porsche is to Volkswagen, so is Cadillac to Chevrolet."

The question arises whether these two explanations are merely different descriptions of the same thing or whether they describe what are in reality two different things. From a purely formal point of view, assuming that the two explanations are descriptions of the same thing if and only if every analogy of one type is transformable into an analogy of the other type, there would appear to be no great impediment to answering this question. The general idea, "When it comes to buying automobiles, you get what you pay for," can, indeed, be expressed in a variety of analogies of both types. The proportional analogy

As the price of Car A is to the price of Car B, so is the quality of Car A to the quality of Car B.

does appear to be very similar to such predictive analogies as

Car A and Car B are both in the $\$ 50,000$ price range. Car $\mathrm{A}$ is of excellent quality. Therefore, Car B is probably also of excellent quality.

With a great deal of tortured syntax, even the example naming four automobiles may be collapsed by paraphrase into an at least apparently predictive form:

If Car A and Car C, made by different manufacturers, both have the property of being more expensive respectively than Car B and Car D, made by the same different manufacturers respectively, then Car A and Car C probably also have the property of being of higher quality than Car B and Car D respectively.
Even though cars $\mathrm{A}$ and $\mathrm{C}$ are never compared to the same car, they are both compared to some other car in the same respect. Nevertheless, I can think of no way to transform a proportional analogy involving an ordered pair of attributes into predictive form:

As the Porsche surpasses the Volkswagen in speed, so does the Cadillac surpass the Chevrolet in luxury.

In fact, such a transformation is impossible because Porsche and Cadillac are not said to have any property in common.

Thus I conclude on purely formal grounds that, even though many analogies of one type can be transformed into the other type, there is at least one important category of analogies that cannot be so transformed. Consideration of other than purely formal properties will reveal further obstacles to treating the two types of analogy as essentially identical.

Even in those cases where a proportional analogy and a predictive one may be paraphrases of each other or equivalent to each other in underlying logical form, the two are not used interchangeably. This is true because the two forms do not have the same function either in reasoning or in discourse. The predictive analogy focuses on something to be predicted, namely that a certain object will be found to have a certain characteristic. The proportional analogy, on the other hand, focuses on a common principle underlying different cases. Of course, both the common principle and the prediction may very well exist in the same example, and in fact the common principle may very well be that which enables one to make the prediction. But that is not the point. In the one case, making the prediction is the goal, and in the other, the emphasis is on calling attention to the principle.

How do the two types relate to reasoning, argument, or logic? The predictive analogy is an argument by almost anybody's definition. The proportional analogy is not 
a complete argument, even though it is intimately associated with argument, reasoning, and logic. In saying this, I am not accepting the view referred to by Toulmin, Rieke, and Janik when they say that figurative analogies "are thought of as falling into a different, nonargumentative category. They may be helpful as ways of making some point clearer, but they cannot actually warrant any claim"' (149). Far from it. First of all, "figurative analogy" is a remote, weakened version of proportional analogy. Measell ("Development" 40) and Wenzel (personal communication) have both challenged the adequacy of this term, but it continues to be used without qualification in textbook after textbook in their own discipline. Second, I do not believe that there is some form of analogy that is "merely" illustrative, explanatory, metaphorical, or literary-even though I do believe the proportional analogy is heuristic in a way the predictive analogy is not. Rather, I am asserting that, while predictive analogy always follows the same pattern as being a complete argument form in itself, proportional analogy is a relation that underlies and enters into a variety of argument patterns.

Ehninger and Brockriede (142-4) and Michalos (347-52) have dealt with proportional analogy in ways that are truly noteworthy. By going beyond the usual conceptions in their own disciplines, Speech Communication-Rhetoric and Critical Thinking-Logic respectively, they converged toward a unified, fundamental explanation. Being, probably, unaware of each other's work, they did not quite reach this point.

Ehninger and Brockriede distinguish " analogy" (corresponding to my " proportional analogy") from "parallel case" (corresponding to my "predictive analogy"). For proportional analogy, they use the example that, as dangers from nuclear weapons tests $(\mathrm{A})$ are to precluding dangers by testing only underground (B), so are dangers from arms races $(\mathrm{C})$ to precluding dangers by limiting armaments (D). As A is to $\mathrm{B}$, so is $\mathrm{C}$ to $\mathrm{D}$, or in other words, just as dangers from nuclear weapons tests can be precluded by testing only underground (evidence), so can dangers from an arms race be precluded by a limitation on armaments (claim). The warrant is that the two relations are similar, and the support for the warrant is that both situations involve the avoidance of danger by limitation rather than complete elimination. And appropriate reservations and qualifications are provided.

Michalos distinguishes "argument by analogy based on analogous relations" (corresponding to my "proportional analogy') from "argument by analogy based on analogous properties" (corresponding to my "predictive analogy"). For proportional analogy, he uses the schematum: "Some (or most, or a certain percentage $r$ ) of the relations a has to $b, c$ has to $d$. a has relation $\mathrm{R}$ to $\mathrm{b}$. It is probable (more probable than not, or probable to a degree $r$ ) that $c$ has $\mathrm{R}$ to d." One of his examples is: "Harry Truman was related to Franklin Roosevelt as Lyndon Johnson was related to John Kennedy. Johnson was vice president under Kennedy. Hence, it is probable that Truman was vice president under Roosevelt."

It is noteworthy that these authors distinguish between analogies based on properties, and analogies based on relations, providing structural logical analyses for a form that most rhetoricians consign to the vague, unanalyzed nonargumentative category "figurative analogy" and that most logicians do not even mention. Although Ehninger and Brockriede employ the terminology of claim, warrant, etc. and Michalos deals in premises and conclusions, both treatments interpret argument by proportional analogy as the drawing of an inference about the analandum (the C:D relation) that is based on some ground in the analans (the $\mathrm{A}: \mathrm{B}$ relation). One difference I find perplexing is that, whereas Michalos treats the proportional analogy based on similarity of relations as a weakened form 
of the proportional analogy based on identity of relations, Ehninger and Brockriede appear to identify a similarity of relations in the warrant and an identity of relations in the support for warranty in the same argument.

That one question aside, Ehninger and Brockriede's example is, I believe, correctly analyzed and appropriately chosen as a plausible instance of discourse. Michalos's example, however, while structurally similar and similarly analyzed, is perverse as an instance of discourse. It is something nobody would ever say. The fact that Truman was FDR's vice president, presented here as a conclusion, and the fact that Truman was FDR's successor, not mentioned in the example, would both be premises in any real world discourse and the conclusion would have something to do with the probable consequences for one's presidency of assuming office on the death of one's predecessor. Furthermore, the entire nature of the argument depends crucially on when it is being made-on whether it is 1963 and one is predicting something about Johnson or whether it is 1990 and one is retrospectively considering all four presidents in order to arrive at some generalization. One might recall here what Strawson said about the present king of France. This leads me to a radical departure from these analyses: although Ehninger and Brockriede have successfully analyzed a single example, they have not demonstrated that their analysis will work for all, or even most, other examples. Michalos has demonstrated, moreover, that the analysis will not always work. Argument by proportional analogy need not always consist of drawing an inference about the analandum based on grounds found in the analans. I see no impediment, for instance, to asserting an entire $A: B:: C: D$ proportion as a claim.

A real example from literary discourse may serve better than invented examples to make this point clear. In criticizing abuses of fiction, Samuel Johnson used the follow- ing proportional analogy: "The Roman tyrant was content to be hated, if he was but feared; and there are thousands of the readers of romances willing to be thought wicked, if they may be allowed to be wits", ("The Rambler No. 4"' 65). It would seem to me just as perverse to infer something about readers of romances on the ground of some fact about Roman tyrants as it would be to infer that Truman was FDR's vice president on the ground that Lyndon Johnson was Kennedy's vice president. I interpret Samuel Johnson's analogy to be advancing a claim about human nature: people are willing to accept blame for lacking a morally worthy virtue in order to receive praise for possessing a less worthy attribute that they themselves highly prize. The grounds for this claim, then, are the examples of Roman tyrants and readers of romances. The warrant is that, when apparently different kinds of people in apparently different kinds of situations exhibit similar behavior, there must be some nonobvious similarity behind the apparent differences.

The reason tyrants were mentioned in the analans and readers in the analandum rather than the reverse in the preceding example is that readers were the topic of discourse, about which tyrants were used to make a comment. The directionality of this analogy was a function of the occasion of discourse whereas, in the example from Ehninger and Brockriede, the directionality from analans to analandum was correctly interpretd as a function of the inference being drawn. Note that in either of these examples the meaning would have been utterly confounded by the common misreading of the proportion which substitutes the erroneous sentence, "A is to $B$ as $C$ is to $D$," for the proper sentence, "As A is to B, so is C to D." Even though invented examples often make about as much sense when read backwards as when read forwards-I might as well have reasoned from the quality of a car to its price as to have reasoned from its price to its 
quality-in significant discourse this is usually not the case. Analogies of all types do have directionality, for three different reasons in different cases: 1) an inference leads from one term to another 2) one term provides a heuristic ground for another 3 ) one term is the topic of discourse while the other term makes a comment on it. Of course one can, if one wishes, change $A: B:: C: D$ to $C: D:: A: B$, but if one does so, one thereby creates a different argument.

For example, as early as St. Paul's first epistle to the Corinthians (Chapt. 12) and as late as the Mayflower Compact, an influential conception represented the community, society, or state as a human body (Hale). As Phillip A. Pecorino has informed me, on the other hand, in the philosophy of Whitehead "the soul is a society" (375). "Also, when we survey the living world, animal and vegetable, there are bodies of all types. Each living body is a society, which is not personal" (264). The insight that a body is a society is very different from the insight that a society is a body.

Whether or not one accepts my position that kinds of analogy are distinct from each other on structural, logical, and pragmatic grounds, there can be no doubt that the conception most commonly found in Critical Thinking and Introduction to Logic textbooks contrasts with another conception historically. I shall attempt to analyze structurally the two concepts as they are found in Aristotle and to illustrate the emergence of the concept that predominates in logic books today through references to a few writers between Bacon and Mill. I associate the ascendence of the predictive analogy with the rise of modern science, even though the structural form of it was discussed by Aristotle. Both these historical areas, as well as the vast labyrinth of Roman, Patristic, Medieval, and Renaissance writers intervening between them, have been explored by scholars in Rhetoric and Speech Communication, especially Measell. I am greatly indebted to Joseph Wenzel for making me aware of the ideas and materials in this discipline relevant to the present discussion.

Greek terms corresponding to at least six English counterparts-paradigm, analogy, proportion, induction, example, and metaphor-enter into Aristotle's treatment of what Lloyd calls analogy "in its broadest sense" (175-6). He treated what I am calling proportional analogy in Poetics (1475b), Rhetoric (1407b), and Topics (108a). Poetics and Topics explicitly state the $A: B:: C: D$ proportion, and Rhetoric clearly implies it by mentioning the "proportional metaphor" and using one of the same examples found in Poetics. His example of old age as the evening of life (Poetics) has a poetic quality quite different from the philosophical tone of "as knowledge stands to the object of knowledge, so is sensation related to the object of sensation" (Topics), but structurally they are the same-a point overlooked in modern textbook treatments of "figurative analogy." Aristotle treated what I am calling predictive analogy under the designation example in Prior Analytics in a passage (69a) immediately following a passage $(68 \mathrm{~b})$ treating induction. This passage on example, which Lloyd called "the first formal analysis of analogical argument in Greek philosophy"' (407), analyzing the argument that it would be an evil (apparently in the sense of "misfortune" rather than "immorality") for the Athenians to war against the Thebans just as it was an evil for the Thebans to war against the Phocians, is entirely different from those in the other three works. Aristotle uses four letters: "Let A be evil, B making war against neighbors, $\mathrm{C}$ Athenians against Thebans, D Thebans against Phocians." But he says nothing of a proportion. Indeed, setting up these four terms in an $A: B:: C: D$ proportion would result in a patent absurdity. It would make sense to say: as Thebes was to Phocia, so would Athens be to Thebes. But these were not the four terms Aristotle identified. The example pertains to two wars, not to four city-states. As 
Lloyd points out, Aristotle considered it inductive, or paradigmatic, because the generalization, or major premise, that it is an evil to war against neighbors, was formed inductively from particular instances such as the war between the Thebans and the Phocians. (The incompleteness of such induction was objectionable to Mill (794) and has recently been reemphasized in a paper by Strong). This has no bearing, however, on Aristotle's treatments of proportion, for these treatments involve no such inductive construction of a premise and the Prior Analytics passage involves no proportion. Aristotle seems to have seen the proportion as an element of rhetoric and the example as a form of logic. On the grounds that it does not seem to make very much sense to say that it is disadvantageous for states to war on other states because the other side usually wins, I infer that Aristotle probably considered the paradigm fallacious, but those who are more widely and deeply read in Aristotle than I am may be aware of other passages that give them good reason to think otherwise.

What happened to these two concepts between Aristotle and the seventeenth century? According to Measell, the distinction between them became lost, or at least blurred, quite early when Latin writers-Varro, Seneca the Younger, and Quintillian being the three primarily responsible-merged them under the single label analogia ("Classical" 8). My own very limited knowledge of these centuries leads me to the conclusion that it was analogia rather than paradeigma that had the upper hand. At least I know that Aquinas's analogy of proportion is structurally the same as Aristotle's proportion whereas his analogy of attribution is not equivalent to Aristotle's example, or paradigm. Measell does, however, name several Renaissance writers who "preserved the precepts of induction and example as Aristotle had viewed them" even though "none of these writers used the term 'analogy' to refer to example" ("Development" 38). (I have reversed the order, and thus the emphasis, of the two statements I just quoted from Measell).

Let us turn our attention to a period of ferment of ideas leading more or less directly to Mill, whose System of Logic Measell and I agree "must be regarded as a watershed in the development of the concept of analogy" ("Development" 40). The assertion that quotations from this period do represent something new in spite of their traceability in some respects to Aristotle can hardly be demonstrated conclusively but must be left to the reader's judgment. Not surprisingly, such references, beginning to appear at about the same time as the rise of interest in scientific method and inductive reasoning in general, associate analogy with induction.

In Bacon's Novum Organum in 1620 , Section 27 of Book Two is devoted to "similar or proportionate instances, which we are also wont to call physical parallels, or resemblances" (157-8). Bacon declares that the study of natural history must be "directed towards inquiring into the observing resemblances and analogies, both in the whole and its parts, for they unite nature, and lay the foundation of the sciences." Bacon's insistence "that we only consider as similar and proportionate instances, those which (as we first observed) point out physical resemblances" and his concern with causation-"Africa and the Peruvian continent... possess a similar isthmus and similar capes, a circumstance not to be attributed to mere accident"both suggest an inductive outlook. Bacon soon, however, veers away from the physical and inductive by pointing out the fact that "the mathematical postulate that things which are equal to the same are equal to one another, is similar to the form of the syllogism in logic, which unites things agreeing in the middle term." Bacon's treatment of analogy is clearly transitional between the old Scholasticism and the New Science.

An uncertainty about whether analogy is inductive or deductive is illustrated by 
the treatment of terms in the leading dictionaries and encyclopedias of the eighteenth century. The Lexicon Technicum of 1704, the first important English-language encyclopedia, compiled under the auspices of the Royal Society by John Harris, defines analogism as "a forcible Argument, from the Cause to the Effect, implying an unanswerable necessity." Harris took this amazing definition from Thomas Blount's Glossographia of 1656, and it was repeated, in shortened form, in Samuel Johnson's dictionary in 1755, the first edition of the Encyclopaedia Britannica in 1771, and Noah Webster's dictionary of 1828. Harris, Johnson, and Webster defined analogy in the proportional sense, Johnson giving the example that learning is to the mind as light is to the eye and Harris remarking that analogy is a synonym of proportion. The Britannica, however, gives more than one sense of the word and includes the predictive one, using the example, "We never doubt that the fruit of the same tree has the same taste." The Britannica also defines analogical syllogism with the remarkable entry, "One whose force chiefly depends on the analogy between the two premisses." In light of this survey, it is perhaps an understatement to say that definition of the analogy in the eighteenth century was unsettled.

An eighteenth-century writer who not only explicitly labels the analogy as a form of induction but practically equates the two with each other is William Duncan. In The Elements of Logick of 1748, Duncan declares that many important assurances are arrived at "by Analogy, and an Induction of Experiments.... We are led to frame a general Conclusion, arguing from what has already happened, to what will happen again in the like Cases.... This is called Reasoning by Analogy; and it is, as we see, founded entirely upon Induction, and Experiments made with particular Objects..." (qtd. in Howell 352-3). It is, I believe, the error, illustrated here, of assuming that induction and analogy are simply the same thing that was to lead to Mill's reaction against analogy. The enthusiasm for science and inductive reasoning unrestrained by rigorous methodology illustrated by this passage must also have contributed to this reaction, as well as helping inspire his systematization of induction familiar to this day under the lable "Mill's Methods."

Whately, an immediate predecessor of Mill whom Mill frequently quotes, explicitly contrasted proportional and predictive analogy on the same dimension I am applying. Having discussed the predictive example that "What is poisonous to humans is probably also poisonous to other animals," Whately continues, "But more strictly speaking, Analogy ought to be distinguished from direct resemblance, with which it is often confounded.... Analogy being a "resemblance of ratios"' (27-8). He then cites and discusses Aristotle's treatment of the proportional analogy from the Topics. Mill acknowledges the same distinction. The difference is that Whately describes the predictive type first, then says "but more strictly speaking," and proceeds to describe the proportional type; but Mill describes the proportional type first in a single paragraph (554-5), then says "It is on the whole more usual, however," and devotes the entirety of his remaining several pages of discussion (555-61, 794-9) to the predictive type. Mill had, however, made one other brief reference to the proportional type (71).

In an early draft of the System of Logic, preceding the first edition, Mill wrote, "Analogical Reasoning, therefore, when contradistinguished from Induction, means inference of the same kind exactly, but of an inferior degree of strength. Analogical Reasoning is an imperfect Induction; or a conjectural foretaste of an Induction yet to come" (1101). This idea, carefully qualified, greatly elaborated, and much refined, remained basic to all his future treatment of the subject. Just how imperfect and inferior Mill considered analogical reasoning to be in comparison with other kinds of induction remains a question. I find Mill's attitude much more negative than 
Measell does, but the reader may consult Mill directly and draw his or her own conclusion.

What I find most intriguing in Mill is that he seems to regard as fitting for analogical treatment only those issues that are in principle subject to direct empirical investigation and verification but for some reason are in fact inaccessible to such investigation-the example he treats at greatest length, and repeatedly, being the question whether the other planets and the moon are inhabited. When an idea rather than a supposed fact is treated analogically, as in the example of the body politic, he does not treat it as either a "figurative" or a proportional analogy but rather treats it as having the same predictive form as the example of the planets. And all such examples he considers he analyzes as fallacies. Treating proportional analogies as predictive ones and then concluding that they are fallacies is an effective way to cause the proportional analogy as a category to disappear. Given the fact that analogy and "Mill's Methods" are commonly treated in the same chapter in logic textbooks, it is perhaps not unreasonable to suggest a possible connection between Mill's approach to analogy and the approach found in logic textbooks.

Let me comment on uses to which analogies of different types are put in everyday life and in argument. My main example here is one from Legal Reasoning, which reflects but also departs from the approach I have ascribed to Mill. My emphasis here, as throughout the article, is not on evaluating the cogency of analogical arguments but rather on characterizing the purposes of users of analogy in reasoning and discourse.

When using predictive analogy, people have a sense of probability that a certain object will turn out to have a certain characteristic. The strength of this sense depends not so much on counting the number of characteristics two objects have in common or counting the number of ob- jects that share a characteristic as it depends on the degree of certainty and preciseness with which the objects being compared are perceived as belonging to the same category. When one picks up a rental car at an airport, one expects that it will operate in roughly the same way as other cars one has driven before and that turning the steering wheel clockwise will not cause the car to turn to the left. As situations become more complex and unpredictable, analogies still inspire some confidence, even in the most technical of disciplines. Klein reports that the design of the B-1 Bomber based on the analogue of the FB-111 demonstrated analogical reasoning to be more efficient and accurate than formal models for certain kinds of engineering applications (205-6). The engineers in this case were more concerned with the practical consequences of their predictions than with the theoretical soundness of their procedures. Users of proportional analogy, on the other hand, have a sense of intuitive insight into a perceived relationship. The strength of this sense does not increase as the objects entering into the comparison become more precisely members of the same category. Indeed, the "aha!' reaction one experiences upon perceiving such analogies becomes greater as the objects themselves become more dissimilar.

Among users of analogy are jurists. The notion that a present case must be treated on analogy with a series of previous similar cases is embodied in the doctrine of stare decisis. In explaining precedent in terms of analogy, Golding follows, I suspect, the example Mill set in treating as predictive analogy an instance that might more naturally be interpreted as proportional analogy. Golding does not, however, like Mill, then reject the analogical reasoning as fallacious. Rather, he defends its soundness in a closely reasoned passage that seems to guard against objections to be anticipated from skeptical logicians. The case is one in which a steamboat proprietor was held liable for money stolen from a passenger's room (47, 
102-11). The precedent cited consisted of previous cases in which innkeepers had been held liable for money stolen from the rooms of guests. Seen as predictive analogy, the reasoning may be sketched as follows:

Innkeepers and proprietors of steamboats both have great opportunity for fraud and plunder toward occupants of rooms; innkeepers have been held strictly liable for money stolen from guests; therefore, steamboat proprietors should probably also be held strictly liable in such cases.

The judge in his decision in this case referred to the "close analogy" that "the two relations... bear," from which I infer he was thinking in terms of the proportional analogy:

As the innkeeper is to the guest, so is the steamboat proprietor to the passenger.

rather that the predictive analogy as interpreted by Golding. Or, to put this in a form suitable for argument by modus ponens:

If the steamboat proprietor is to the passenger as the innkeeper is to the guest, to a sufficient degree and in relevant respects, then the court should hold the proprietor strictly liable.

Note that the A:B::C:D proportion appears in a premise in my proposal. It is beyond the scope of the present article to fill out the details of this suggested line of argument so as to make it a credible competitor to the one Golding ably defends in several closely packed pages. I can only tentatively suggest that all relevant characteristics shared by innkeepers and steamboat proprietors would appear in the grounds and the claim would be that the court should hold liable anyone who has such characteristics. The court would be warranted in such a decision by some principle of common law, and the warrant would be backed by the precedents of the former decisions that established that principle.

The predictive and proportional forms may appear to be equivalent here, but I do not consider them so. My reason is that I question the legitimacy of drawing a normative conclusion on the basis of inductive evidence in the manner illustrated. When the judge said "probably," he was using a modal qualifier to guard his utterance, in accord with the Toulmin model; he was not assuming Mill's conception of induction as something in principle subject to empirical verification. The normative conclusion that the proprietor should be held liable is not subject to such verification. Being held liable is not just one more characteristic of proprietors, on a par with such characteristics as having access to a passenger's room, providing service for pay, etc. Unlike the fact that a proprietor has access to a passenger's room, the fact of liability is created by a ruling of the court and therefore depends at least as much on the characteristics of courts as on the characteristics of proprietors. The likelihood that a proprietor will be found liable is indeed predictable to a degree, but any intelligent prediction of such an outcome would have to take into account prior rulings of courts at least as much as facts about proprietors. When we say

The proprietor of a steamboat should probably be held strictly liable for possessions stolen from a passenger,

there is a question whether the word probably has the same effect that it has when we say

There will probably be six inches of snow by tomorrow morning.

By tomorrow morning, probability in the latter case will have turned to certainty. In the former case, we will never be any more certain than we are now. One has liability not as an effect (like snow) that is caused (as by atmospheric conditions) but for reasons. When we use the word probably in such a context, we seem to be qualifying the degree of goodness we are willing to accord to the reasons given for considering the proprietor liable. Degrees of goodness of reasons are not the same thing as degrees of probability that an effect will 
be observed.

In order to question whether predictive analogies should be allowed to lead to normative conclusions, I do not have to maintain that inductive reasoning, degrees of probability, and empirical evidence apply only to events in the world and are irrelevent to normative conclusions. I only have to maintain that something more than just such elements is necessary to normative judgments. Perhaps the word should holds a clue to what this "something more" is. By saying that the proprietor probably should be held liable, perhaps the court means to say not only that its decision is the logical answer to a question about the legal nature of proprietors but also that its decision is intended to enforce some principle of justice that courts should enforce.

Analogy has philosophical roots. There is a relation between forms of reasoning in themselves and the uses to which they have been put within different intellectual traditions. A given mode of reasoning and expression has an affinity with a given world view. Related but different modes tend to be viewed as variants to be subsumed under a dominant mode within a given tradition. The medieval cosmology, according to which the microcosm reflects the structure of the macrocosm, goes far toward explaining the popularity of both analogy and allegory in the Middle Ages. Such systems of belief are a sufficient, though not a necessary, condition to the flourishing of proportional analogy. The scientists Emerson refers to in "The American Scholar" would, ironically, probably employ a different kind of analogy to describe their discoveries than the one Emerson ascribes to them:

The astronomer discovers that geometry, a pure abstraction of the human mind, is the measure of planetary motion. The chemist finds proportions and intelligible method throughout matter: and science is nothing but the finding of analogy, identify in the most remote parts (66).

I present one final example and leave the analysis of it, especially the reservations and qualifications, as an exercise for the reader: As the predictive analogy is to empiricism, so is the proportional analogy to idealism.

\section{Works Cited}

"Analogy." Encyclopaedia Britannica. 1st. ed. London, 1771.

Aristotle. Poetics. Trans. Ingram Bywater. The Words of Aristotle Vol 2. Great Books of the Western World 9. Chicago: Encyclopaedia Britannica, 1952.

Prior Analytics. Trans. A.J. Jenkinson The Works of Aristotle Vol 1. Great Books of the Western World 8. Chicago: Encyclopaedia Britannica, 1952.

Rhetoric. Trans. W. Rhys Roberts. The Works of Aristotle Vol 2. Great Books of the Western World 9. Chicago: Encyclopaedia Britannica, 1952.

Topics. Trans. W.A. PickardCambridge. The Works of Aristotle Vol 1. Great Books of the Western World 8. Chicago: Encyclopaedia Britannica, 1952.
Bacon, Francis. Francis Bacon. Great Books of the Western World 30. Chicago: Encyclopaedia Britannica, 1952

Barnet, Sylvan, and Marcia Stubbs. Practical Guide to Writing. 6th ed. Glenview, IL: Scott, Foresman, 1990

Barry, Vincent E. Practical Logic. 2d ed. New York: Holt, Rinehart and Winston, 1980.

Baum, Robert. Logic. New York: Holt, Rinehart and Winston, 1975.

Cederblom, Jerry, and David W. Paulsen. Critical Reasoning. 2d ed. Belmont, CA: Wadsworth, 1986.

Chaffee, John. Thinking Critically. 2d ed. Boston: Houghton Mifflin, 1988.

Cronkhite, Gary, Public Speaking and Critical Listening. Menlo Park. CA: Benjamin /Cummings, 1978. 
Ehninger, Douglas, and Wayne Brockriede. Decision by Debate. New York: Dodd, Meade, 1963.

Emerson, Ralph W. Selections From Ralph Waldo Emerson. Ed. Stephen E. Whicher. Boston: Houghton Mifflin, 1957.

Ferre, Frederick. "Analogy in Theology." The Encyclopedia of Philosophy. Ed. Paul Edwards. 8 vols. New York: MacMillan, 1967.

Golding, Martin P. Legal Reasoning. New York: Knopf, 1984.

Gronbeck, Bruce E., et. al. Principles and Types of Speech Communication. 11 th ed. Glenview, IL: Scott, Foresman, 1990.

Hale, David G. "Analogy of the Body Politic." Dictionary of the History of Ideas. New York: Scribners, 1973.

Harris, John. Lexicon Technicum: A Universal English Dictionary of Arts and Sciences. 2 vols. London, 1736.

Howell, Wilbur Samuel. Eighteenth-Century British Logic and Rhetoric. Princeton: Princeton UP, 1971.

James, William. The Principles of Psychology. 2 vols. New York: Holt, 1896.

Johnson, Samuel. A Dictionary of the English Language. New York: AMS Press, 1967.

_- "The Ramber No. 4." Samuel Johnson: Selected Prose and Poetry. Ed. Bertrand H. Bronson. New York: Rinehart, 1955: 60-5.

Kahane, Howard. Logic and Contemporary Rhetoric. 5th ed. Belmont, CA: Wadsworth, 1988.

Klein, Gary A. "Applications of Analogical Reasoning." Metaphor and Symbolic Activity 2.3 (1987): 201-18.

Leggett, Glen, et. al. Prentice Hall Handbook for Writers, 10th ed. Englewood Cliffs: Prentice Hall, 1988.

Levin, Gerald. The MacMillan College Handbook. New York: MacMillan, 1987.

Lloyd, G.E.R. Polarity and Analogy: Two Types of Argumentation in Early Greek Thought. Cambridge: Cambridge UP, 1966.

L[otz], J[ohannes] B. "Analogy." Philosophical Dictionary. Ed. Walter Brugger. Freiburg In Breisgau: Verlag Herder KG, 1967. Trans. and ed. Kenneth Baker. Spokane: Gonzaga UP, 1972.
Manicas, Peter T., and Arthur N. Kruger. Logic: The Essentials. New York: McGraw Hill, 1976.

Measell, James S. "Classical Bases of the Concept of Analogy." The Journal of the American Forensic Association 10 (1973): 1-10.

"Development of the Concept of Analogy in Rhetorical Theory." Rhetoric and Communication. Ed. Jane Blankenship and Herman G. Stelzner. Urbana: UIP, 1976: 34-45.

Michalos, Alex C. Principles of Logic. Englewood Cliffs: Prentice Hall, 1969.

Mill, John Stuart. A System of Logic Ratiocinative and Inductive. Ed. J.M. Robson. Collected Works of John Stuart Mill Vols 7, 8. Toronto: UTP, 1978.

Osborn, Michael, and Suzanne Osborn. Public Speaking. Boston: Houghton Mifflin, 1988.

Pecorino, Philip A. Personal Communication.

Ross, Raymond S. Speech Communication: Fundamentals and Practice. 6th ed. Englewood Cliffs: Prentice Hall, 1983.

Runkle, Gerald. Good Thinking: An Introduction to Logic. 2d ed. New York: Holt, Rinehart and Winston, 1981.

Spurgin, Sally DeWitt. The Power to Persuade. 2d ed. Englewood Cliffs: Prentice Hall, 1989.

Strong, Charles W. "Metaphor, Analogy, and Classification." Paper at Conference 88 on Critical Thinking, Christopher Newport College. Newport News, VA, 9 April 1988.

Toulmin, Stephen, Richard Rieke, and Allan Janik. An Introduction to Reasoning. New York: MacMillan, 1979.

Waller, Bruce N. Critical Thinking: Consider the Verdict. Englewood Cliffs: Prentice Hall, 1988.

Wenzel, Joseph. Personal Communication.

Whately, Richard. Rhetoric. Bound with Samuel Taylor Coleridge, Encyclopedia Metropolitana. London, 1851.

Whitehead, Albert North. Adventures of Ideas. New York: MacMillan, 1961.

WILLIAM R. BROWN

DEPARTMENT OF ENGLISH

QUINNIPIAC COLLEGE

HAMDEN, CT 06518 